\title{
Agricultura Familiar e Sustentabilidade Rural: um Estudo a Partir da Caracterização de Propriedades Rurais
}

\author{
Family Agriculture and Rural Sustainability: a Study from the Rural Properties \\ Characterization
}

\author{
Luciana Ferreira da Silva*ab; Denise Renata Pedrinhoa; Márcia Alves Rocha ${ }^{a}$
}

\begin{abstract}
${ }^{a}$ Universidade Anhanguera-Uniderp, Programa de Pós-Graduação Stricto Sensu em Produção Agroindustrial. MS, Brasil.
${ }^{b}$ Universidade Estadual do Mato Grosso do Sul, Programa de Pós-Graduação em Agronegócio. MS, Brasil.

*E-mail: luciana@uems.br
\end{abstract}

\begin{abstract}
Resumo
O objetivo deste artigo foi analisar a experiência da agricultura familiar com enfoque na gestão e sustentabilidade das propriedades rurais do assentamento Lagoa Grande - Dourados/MS. A pesquisa é de caráter exploratório e descritivo com abordagem qualitativa e quantitativa. É notório que a agricultura familiar tem significativa importância na produção de alimentos, principalmente, para a mesa do brasileiro e, também, do sul-mato-grossense, ainda assim, se permeiam desafios sobre a sustentabilidade, eficiência na utilização dos recursos naturais, produção e gestão do pequeno negócio. Para isto, são ressaltadas as parcerias na produção com o uso de máquinas e/ou equipamentos, recursos financeiros, ou cursos que possibilitem maior conhecimento e capacitação sobre a gestão e condução do negócio. Para as propriedades rurais do assentamento se constatou o acesso insuficiente às tecnologias de produção, baixo conhecimento e pouca participação no que se refere às associações e cooperativas, estes fatores contribuem para o distanciamento da melhoria produtiva e de renda para tal grupo. Ainda que a sustentabilidade está relacionada à complementação da renda dos produtores, a partir de outras fontes de renda não agrícolas essenciais para garantia da subsistência familiar. Para contornar tais adversidades é necessário desenvolvimento de ações, por meio de políticas públicas, parcerias e cooperações que possibilitem a educação e expansão rural familiar.
\end{abstract}

Palavras-chave: Associativismo. Gestão da Propriedade. Cooperativa.

\begin{abstract}
The objective of this article was to analyze the family farming experience focused on the management and sustainability of rural properties of Lagoa Grande - Dourados - MS. The research is exploratory and descriptive with a qualitative and quantitative approach. It is well known that family farming has significant importance in the food production mainly for the Brazilian table and also for the people from Mato Grosso do Sul, even though challenges remain regarding sustainability, efficiency in the use of natural resources, production and management of the small business. To this end, partnerships in production with the use of machines and / or equipment, financial resources, or courses that enable greater knowledge and training on the business management and conduct are highlighted. For the rural properties of the settlement, insufficient access to production technologies, low knowledge and little participation in associations and cooperatives were found to contribute to the distancing of production improvements and better income for such group. Still, that sustainability is related to the producers'income complementation, from other non-agricultural sources of income essential to guarantee family subsistence. To circumvent such adversities, it is necessary to develop actions through public policies, partnerships and cooperation that enable education and family farmers expansion.
\end{abstract}

Keywords: Associativism. Property Management. Cooperative.

\section{Introdução}

A agricultura familiar possui características peculiares e distintas quando comparadas as demais atividades produtivas do setor agropecuário. Segundo o Ministério do Desenvolvimento Agrário - MDA (2016), apoiado em dados do Instituto Brasileiro de Geografia e Estatística - IBGE, aproximadamente $84 \%$ dos estabelecimentos agropecuários brasileiros pertencem a grupos familiares.

No Brasil, a agricultura familiar constitui a base econômica de $90 \%$ dos municípios com até 20 mil habitantes; responde por $35 \%$ do produto interno bruto nacional; e absorve $40 \%$ da população economicamente ativa do país. Esses dados indicam a relevância econômica e social da agricultura familiar no cenário nacional (MDA, 2016).

De acordo com Sangalli e Schlindwein (2013), a agricultura familiar agrega o maior número de pessoas ocupadas no Brasil, enquanto em Mato Grosso do Sul predomina o maior número de pessoas ocupadas na agricultura patronal. Entretanto, o PIB da agricultura familiar, no período de 2002 a 2005, foi superior ao crescimento dos índices do PIB patronal. Este fato ressalta a importância e a representatividade da agricultura familiar no agronegócio do Estado de Mato Grosso do Sul.

Apesar da sua importância, Souza et al. (2011) relacionaram as barreiras que restringem o desenvolvimento da agricultura familiar, as quais estão ligadas, principalmente, no que se refere a escassez de terra, a carência de assistência técnica e a escassez de recursos financeiros. Tais fatores restringem o alcance do padrão tecnológico necessário para que este segmento obtenha vantagem competitiva.

Para Kurten e Ternoski (2016), a agricultura familiar representa grande potencial para o país e o desafio atual 
consiste na busca por uma agricultura sustentável, aliando o aumento da produtividade à preservação dos recursos naturais. Stoffel et al. (2014) afirmaram que no campo da sustentabilidade da agricultura familiar são necessárias ações coletivas e o desenvolvimento de instituições apropriadas, que possibilitam a redução dos custos de transações e que forneçam um melhor acesso às tecnologias e aos mercados de insumos e produtos.

Nesse sentido, buscou-se responder a seguinte questão de pesquisa: os pequenos produtores rurais conseguem sobreviver a partir do uso da terra? Desse modo, os objetivos do presente trabalho foram analisar a experiência da agricultura familiar com enfoque na gestão e sustentabilidade das propriedades rurais no assentamento Lagoa Grande - Dourados/MS; identificar as expectativas dos produtores em relação ao uso da terra, identificar as práticas de gestão realizadas nas propriedades investigadas e verificar a existência de formas associativas e suas contribuições para a manutenção e subsistência das propriedades.

\section{Desenvolvimento}

\subsection{Metodologia}

Esta pesquisa é exploratória e descritiva com abordagens qualitativas e quantitativas envolvendo os 23 produtores rurais das propriedades oriundas da agricultura familiar no assentamento Lagoa Grande do Estado do Mato Grosso do Sul (Brasil).

Essa região foi escolhida por suas características diferenciadas e pela facilidade de acesso por já possuir parceria com pesquisadores em outros projetos desenvolvidos na região. O período da realização da pesquisa ocorreu durante o mês de maio/2017 e a amostra deste estudo foi selecionada, considerando o acesso às propriedade e disponibilidade dos respondentes.

\subsection{Caracterização da Área de Estudos}

O assentamento Lagoa Grande está localizado na cidade de Dourados, no Estado de Mato Grosso do Sul, foi instituído em 6 de novembro de 1997, via desapropriação, compreendendo uma área total de 4.070,7670 ha, subdividida em 151 lotes, os quais possuem, em média, de 25 ha. A área dos lotes do assentamento Lagoa Grande varia de 17 a 90 hectares (Figura 1). Esta divergência nos tamanhos decorre de áreas de preservação permanente que são muito mais extensas em alguns lotes, sendo, portanto, compensados em maior área total (SANGALLI, 2013).

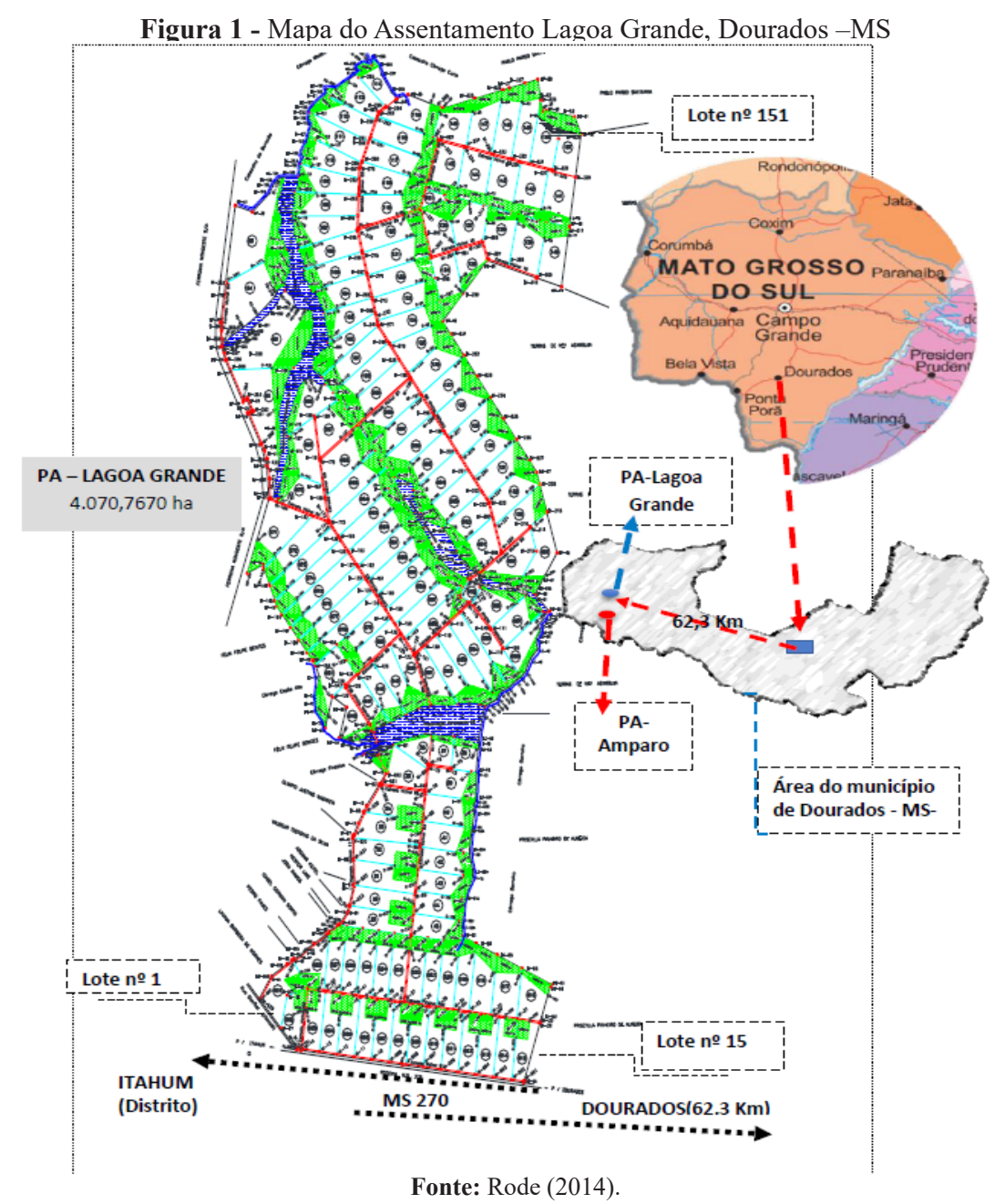




\subsection{Revisão de literatura}

A revisão de literatura foi realizada a partir da consulta das bases de dados Web Science e Scielo disponíveis no portal de periódicos CAPES, utilizando as palavras-chaves associativismo, gestão da propriedade e cooperativa, inerentes à temática da pesquisa em um recorte temporal de 2005 a 2017, além da consulta aos sites de órgãos governamentais e livros que abordam a sustentabilidade, o contexto atual do agronegócio e o desenvolvimento agropecuário.

\subsection{Coleta de dados}

\subsubsection{Elaboração do instrumento de pesquisa}

O instrumento utilizado para esta pesquisa foi um questionário aberto que contemplava aspectos relacionados à caracterização das propriedades, formas de gestão e práticas sustentáveis desenvolvidas.

As categorias de análise dos dados foram divididas em dois blocos, conforme apresentados no Quadro 1.

Quadro 1 - Categorias de análise dos dados

\begin{tabular}{|c|c|}
\hline $\begin{array}{c}\text { Caracterização } \\
\text { dos produtores } \\
\text { propriedades } \\
\text { rurais. }\end{array}$ & $\begin{array}{l}\text { Identificar de que forma ocorreu a chegada } \\
\text { dos produtores no assentamento; a origem } \\
\text { dos produtores, o tempo de posse da } \\
\text { terra e as expectativas com relação ao } \\
\text { assentamento. Identificar as atividades } \\
\text { agrícolas, desenvolvidas em âmbito } \\
\text { familiar; o estabelecimento ou não de } \\
\text { algum tipo de parceria, a dependência do } \\
\text { setor público ou outros agentes privados e } \\
\text { analisar as questões relativas à dimensão da } \\
\text { confiança e da legalidade entre os agentes } \\
\text { envolvidos nas redes organizacionais. }\end{array}$ \\
\hline $\begin{array}{l}\text { Sustentabilidade } \\
\text { rural da } \\
\text { agricultura } \\
\text { familiar. }\end{array}$ & $\begin{array}{l}\text { Verificar se a renda advinda da produção } \\
\text { era suficiente para a sustentação familiar; as } \\
\text { formas de gestão das propriedades; as ações } \\
\text { desenvolvidas para mantera sustentabilidade } \\
\text { da terra; as principais atividades } \\
\text { desenvolvidas na agricultura quanto } \\
\text { às formas associativas da comunidade. } \\
\text { Identificar se os produtores participavam de } \\
\text { algum tipo de capacitação ou treinamento } \\
\text { voltado para a gestão das propriedades; } \\
\text { verificar que tipos de associação havia na } \\
\text { comunidade, suas contribuições para o } \\
\text { crescimento e manutenção da produção e a } \\
\text { percepção do produtor quanto às parcerias } \\
\text { por ele estabelecidas. }\end{array}$ \\
\hline
\end{tabular}

Fonte: Dados da pesquisa.

\subsubsection{Aplicação do instrumento}

O questionário foi aplicado no mês de maio 2017 e os produtores rurais foram selecionados considerando o acesso às propriedades e a disponibilidade dos respondentes. Primeiramente, os produtores foram convidados a participar da pesquisa, após o aceite foi realizada a explanação dos critérios envolvidos e dos objetivos propostos, em seguida, foi solicitado que preenchessem o Termo de Consentimento Livre Esclarecido e, posteriormente, foi realizado o detalhamento sobre o questionário. Os respondentes foram entrevistados por uma equipe de pesquisadores e todas as entrevistas foram gravadas para posterior transcrição dos dados.

\subsection{Análise dos dados}

Os dados obtidos pela análise interpretativa do questionário aplicado aos produtores rurais e de acordo com as categorias estabelecidas foram tabulados utilizando uma planilha no formato Excel com o propósito de apresentar os resultados em forma de gráficos e tabelas.

\subsection{Caracterização das Propriedades}

A análise das propriedades mostrou que dos 23 produtores entrevistados, 96\% são do Estado de Mato Grosso do Sul, enquanto $4 \%$ são provenientes de outros Estados (Quadro 2). Com relação à forma de aquisição dos lotes, entre os respondentes,70\% são originários do INCRA e 30\% por aquisição de terceiros. Quanto ao ano de aquisição dos lotes, $70 \%$ estão assentados desde a instituição do assentamento, que ocorreu no ano de 1997.

Quadro 2 - Caracterização das propriedades.

\begin{tabular}{|c|c|c|c|}
\hline \multicolumn{2}{|c|}{ Variáveis } & Quantidade & Percentual \\
\hline $\begin{array}{c}\text { Origem do } \\
\text { produtor }\end{array}$ & MS & 22 & $96 \%$ \\
Outros Estados & 1 & $4 \%$ \\
\hline $\begin{array}{c}\text { Forma de } \\
\text { aquisição } \\
\text { do lote }\end{array}$ & $\begin{array}{c}\text { Cadastro / Sorteio } \\
\text { Aquisição de } \\
\text { terceiros }\end{array}$ & 16 & $70 \%$ \\
\hline $\begin{array}{c}\text { Tempo de } \\
\text { posse da } \\
\text { terra }\end{array}$ & Menos de 5 anos & 4 & $30 \%$ \\
\hline
\end{tabular}

Fonte: Dados da pesquisa.

Interessante destacar que a maioria dos produtores entrevistados permanecia no assentamento desde a aquisição dos lotes. Quando questionados sobre os motivos pelos quais almejaram a posse da terra, a maior parte dos produtores mencionou a possibilidade de ter uma casa e a oportunidade de produzir e gerar renda. Em relação às expectativas que esses possuíam ao chegar no assentamento, evidenciou-se a melhoria da qualidade de vida a partir da produção.

A agricultura familiar é responsável, não só pelo desenvolvimento rural e social, como também pela produção local de alimentos para a sociedade. Dessa maneira, o pequeno produtor ocupa um papel decisivo na cadeia produtiva que abastece o mercado brasileiro.

As atividades produtivas para geração de renda no assentamento são pouco diversificadas, destacando-se a agricultura com 57\% (Figura 2).

Figura 2 - Representatividade das principais atividades produtivas desenvolvidas no Assentamento Lagoa Grande.

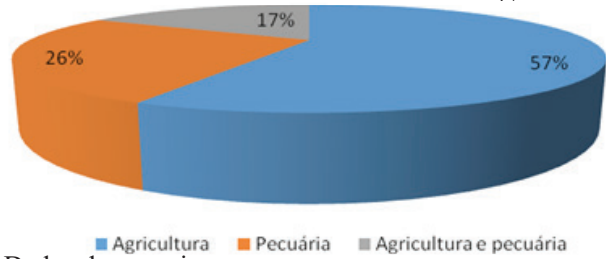

Fonte: Dados da pesquisa. 
Verificou-se a necessidade de maior diversificação produtiva no assentamento, tanto para a garantia da subsistência familiar quanto para a geração de renda. Importante salientar que a maior parte dos produtores não possuía maquinários para a realização da atividade agrícola, no que se refere às culturas de soja e milho, o que demandou o estabelecimento de algum tipo de parceria para o seu desenvolvimento.

Quanto à natureza das parcerias (Figura 3), ficou evidenciado que $43 \%$ dos produtores recorriam ao uso de financiamentos bancários e eram associados a uma cooperativa local, na qual compravam os insumos e vendiam a produção, enquanto outros $4 \%$ recorriam aos financiamentos bancários, contudo, não eram cooperados. Em contrapartida, $17 \%$ dos produtores mencionaram que arrendaram as terras para viabilizar a produção no lote, pois não possuíam recursos para investir na propriedade. Apenas 9\% dos produtores entrevistados relataram que estabeleciam parcerias entre vizinhos no que se refere à utilização de maquinários para o plantio e manutenção da lavoura e, $26 \%$ dos produtores não realizavam nenhum tipo de parceria para o desenvolvimento de suas atividades, o que pode ser explicado pela presença da pecuária como a segunda principal atividade desenvolvida no assentamento.

Figura 3 - Natureza das parcerias realizadas no desenvolvimento das atividades agropecuárias no Assentamento Lagoa Grande

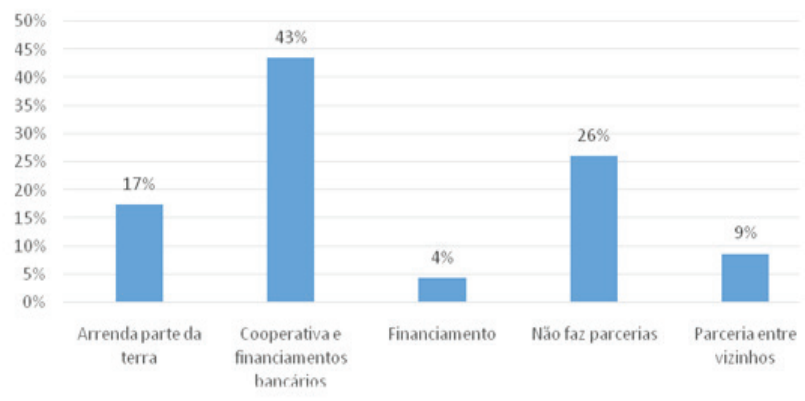

Fonte: Dados da pesquisa

Importante salientar que o percentual de produtores, que arrendavam suas terras para a produção de commoditties, era substancialmente expressivo, por se tratar de um assentamento rural cujo objetivo é o desenvolvimento de um modelo de produção tradicional, voltado à subsistência da família. Esse fator ressalta a importância do fortalecimento da agricultura familiar, por meio de políticas públicas que possam viabilizar a produção de alimentos e a geração de renda nas pequenas propriedades rurais.

A maior parte dos produtores do assentamento realizava parcerias para desenvolver suas atividades (Figura 4), entre as atividades sobressaíram à comercialização da produção com $35 \%$ e o plantio da lavoura com $30 \%$, entretanto, vale ressaltar que $30 \%$ dos produtores afirmaram não desenvolver atividades de forma associativa em suas propriedades.
Figura 4 - Atividades desenvolvidas quanto às formas associativas no Assentamento Lagoa Grande

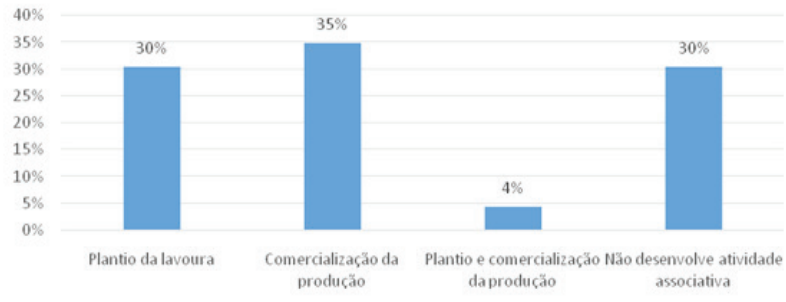

Fonte: dados da pesquisa.

\subsection{Sustentabilidade Rural da Agricultura Familiar}

Quando questionados acerca da sustentabilidade rural na agricultura familiar, 96\% dos entrevistados afirmaram que a produção não era suficiente para a subsistência da família, sendo, portanto, necessário recorrer a outras fontes de renda, a fim de complementar o orçamento familiar.

Figura 5 - Origem das fontes de renda que complementam o orçamento familiar dos produtores rurais do Assentamento Lagoa Grande.

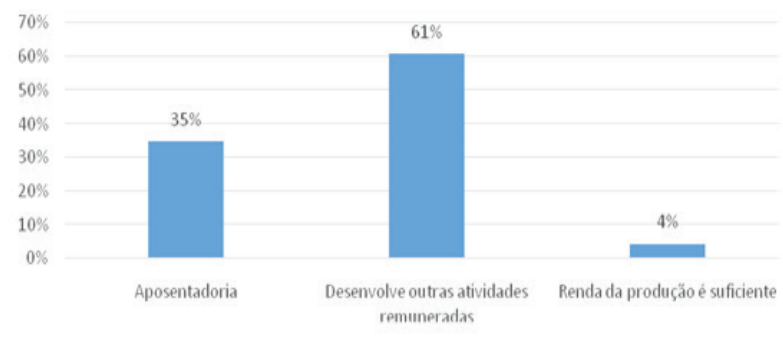

Fonte: Dados da pesquisa.

Apenas 4\% dos produtores rurais do assentamento Lagoa Grande consideravam que a renda advinda do lote era suficiente para a subsistência da família, contudo, verificou-se que a maioria dos $61 \%$ desenvolviam atividades remuneradas, a fim de complementar o orçamento familiar. Importante destacar ainda que $35 \%$ dos produtores eram aposentados, fator este que evidencia o envelhecimento da população no campo, o que em curto prazo pode comprometer a produção caso não haja um potencial sucessor que dê continuidade aos negócios da família na propriedade rural.

O predomínio de fontes de renda não agrícolas no assentamento Lagoa Grande também foi identificado, no estudo Sangalli (2013), que destacou que alguns assentados não realizavam nenhuma atividade geradora de renda na propriedade, como no caso de algumas famílias de aposentados e de pessoas que apenas moravam no assentamento, as quais trabalhavam na vila (Itahum), nas fazendas do entorno ou em Dourados.

Vieira Filho e Fishlow (2017) já advertiram que os atrasos em termos de conteúdo tecnológico contribuem para a permanência dos agricultores em situação de pobreza, sendo, portanto, necessário recorrer a outras fontes de renda não agrícolas para sobreviver.

Questionados sobre as práticas utilizadas para a conservação do meio ambiente, com relação ao solo, 100\% 
dos entrevistados mencionaram tão somente a correção do solo por meio de análises e correção com adubo e/ou calcário, sem especificar a periodicidade da realização desta prática. Os dados demonstraram a necessidade do desenvolvimento de projetos e ações sustentáveis, a fim de contribuir para o desenvolvimento de atividades agropecuárias como a adubação orgânica, que além de minimizar os impactos ambientais, pode colaborar para a redução de custos na aquisição dos insumos.

No que se refere à forma de gestão das propriedades rurais no assentamento Lagoa Grande, ficou evidenciado que 87\% dos produtores entrevistados gerenciavam suas propriedades, por meio do controle de gastos, e faziam anotações no que se referia à compra e venda de insumos produtivos e, da própria produção. Notou-se a falta de planejamento e estratégias de gestão que podiam, então, contribuir para melhorar o controle dos recursos e, consequentemente, da renda proveniente das atividades em âmbito familiar.

Quando questionados sobre a participação em cursos de capacitação ou treinamento voltados para administração da propriedade rural, foi observado que apenas $17 \%$ dos produtores participavam de programas de capacitação de mão de obra e extensão rural promovidos pela associação do assentamento, em parceria com instituições governamentais.

De acordo com Vieira Filho e Fishlow (2017), as limitações dos serviços de assistência técnica e extensão rural comprometiam o desenvolvimento das propriedades, o que prejudicava, por sua vez, a troca de experiência entre os produtores, tornando mais lento o processo de difusão da tecnologia. Nesse sentido, "é preciso dotar o espaço rural de boa infraestrutura educacional, no intuito de estimular o desenvolvimento de forma endógena e autônoma" (VIEIRA FILHO; FISHLOW, 2017, p. 62).

Quando questionados acerca da associação dos moradores do assentamento, periodicidade das reuniões e benefícios providos pela associação se constatou que $78 \%$ dos entrevistados não participavam das reuniões, porque desconheciam a periodicidade das mesmas, alegando, em sua maioria, a falta de comunicação entre o presidente e os assentados, fator que também pode estar relacionado à extensão territorial do assentamento, como também ao desinteresse por parte dos produtores. Desse modo, ficou evidente que a associação não estava contribuída, de modo geral, para o fortalecimento da produtividade no assentamento. Sangalli (2013) também relatou, em seu estudo, que a associação de moradores não cumpriu seu papel no processo de apoio ao desenvolvimento do assentamento.

No que diz respeito ao cooperativismo, ficou evidenciado que não havia uma cooperativa no assentamento, apenas no distrito, cujo foco era a compra de grãos e a venda de insumos. Contudo, 35\% dos produtores entrevistados eram associados à cooperativa do distrito, participavam das reuniões indicando uma relação de confiança entre o associado e a cooperativa, fatores estes que impactavam, positivamente, na produção e produtividade do empreendimento familiar.

Vieira Filho e Fishlow (2017) salientaram que "quanto melhor o ambiente organizacional, em que a produção se insere maior será o conhecimento acumulado dos agentes e melhor será a absorção de tecnologia externa".

Quanto à comercialização da produção, 83\% dos produtores responderam preferir comercializar a produção autonomamente e apenas $17 \%$ por intermédio de um atravessador ou agente do agronegócio. Entre os principais indicadores valorizados pelos agentes do agronegócio no firmamento das negociações sobressaíram, em primeiro lugar, o valor e, em segundo lugar, o cooperativismo.

Quanto à compra de insumos, 61\% dos produtores compravam os insumos em agropecuárias, outros 30\% compravam os insumos tanto nas cooperativas quanto em agropecuárias, dando prioridade ao menor valor encontrado e, apenas $9 \%$ estabeleciam parcerias entre vizinhos para conseguir reduzir os custos de transação mediante a compra de insumos produtivos, considerando a quantidade de produtos adquiridos (Figura 6).

Stoffel et al. (2014) relataram que, no campo da sustentabilidade da agricultura familiar, eram necessárias ações coletivas e o desenvolvimento de instituições apropriadas que possibilitam a redução dos custos de transação, e que forneçam um melhor acesso às tecnologias e aos mercados de insumos e produtos. Para estes autores, o apoio de cooperativas locais e a integração às agroindústrias são exemplos de instituições, que podem contribuir para a sustentabilidade das propriedades rurais.

Ainda, no tocante a essa temática, de acordo com Vieira Filho e Fishlow (2017), a concepção da legislação fundiária no que tange à produtividade decorrente tão somente da distribuição de terra, ocorre de modo equivocado. Os autores enfatizam que o aumento da produtividade está diretamente relacionado ao uso de tecnologia, o qual depende da capacidade de absorção de novos conhecimentos por parte dos assentados.

Para tanto, é substancial o desenvolvimento de políticas públicas voltadas para a promoção da educação e de extensão rural nos assentamentos, aliados à conservação e melhoria ambiental, além da importância da cooperação na agricultura familiar como um meio de obter vantagem competitiva, gerando maior produtividade da terra e/ou do trabalho, associada a menores custos produtivos. Dessa maneira, embora o fator terra seja importante, o acesso ao conhecimento se sobressai como a variável decisiva para o desenvolvimento e a sustentabilidade da agricultura familiar.

\section{Conclusão}

A agricultura familiar carece de um amplo programa de capacitação, de planejamento e de extensão rural, tendo em vista que a maioria dos agricultores entrevistados não 
consegue sobreviver da renda proveniente somente da agricultura familiar, sendo necessário recorrer a outras fontes de renda não agrícolas para garantir a subsistência da família.

\section{Referências}

BRASIL. Ministério do Desenvolvimento Agrário, 2016. Agricultura familiar e desenvolvimento Agrário. Disponível em: http://www.mda.gov.br/sitemda/noticias/o-que-\%C3\%A9agricultura-familiar>. Acesso em 12 jun. 2019.

KURTEN, L. B.; TERNOSKI, S. Agricultura familiar e sustentabilidade. Economias Agrária e dos Recursos Naturais. Unicentro, 2016.

RODE, M. A Gestão da propriedade rural: um estudo de caso a partir da realidade do Assentamento Lagoa Grande, em Dourados. Dourados: Universidade Federal da Grande Dourados, 2014.

SANGALLI, A. R. Assentamento Lagoa Grande, em dourados,
$M S:$ aspectos socioeconômicos, limitações e potencialidades para o seu desenvolvimento. Dourados: Universidade Federal da Grande Dourados.

SANGALLI, A.R.; SCHLINDWEIN, M.M. A contribuição da agricultura familiar para o desenvolvimento rural de Mato Grosso do Sul - Brasil. Redes, v.18, n.3, p.82-99, 2013. doi: 10.1 7058/ redes. v18i3.2592.

SOUZA, P. M. et al. Agricultura familiar versus agricultura não-familiar: uma análise das diferenças nos financiamentos concedidos no período de 1999 a 2009. Documentos TécnicoCientíficos. Rev. Econôm. Nordeste, v.42, n.1, p. 219, 2011.

STOFFEL, J.A. et al. The future of family farming: A literature review on innovative, sustainable and succession-oriented strategies. J. Rural Studies, v.47, p.117-140, 2016.

VIEIRA FILHO, J.E.R. Agricultura e indústria no Brasil: inovação e competitividade. Brasília: Ipea, 2017. 